\title{
Development of an automated on-line pre-column derivatization procedure for sensitive determination of histamine in food with high-performance liquid chromatography-fluorescence detection
}

\author{
Jin-feng Peng a, Ke-teng Fang ${ }^{a}$, Dong-hua Xie ${ }^{a}$, Bin Ding ${ }^{a}$, Ju-Yi Yin ${ }^{a}$, \\ Xiao-mei Cui ${ }^{a}$, Ying Zhang ${ }^{a}$, Jing-fu Liu ${ }^{b, *}$ \\ a Ningbo Entry-Exit Inspection and Quarantine Bureau, Ningbo 315012, China \\ ${ }^{\mathrm{b}}$ State Key Laboratory of Environmental Chemistry and Ecotoxicology, Research Center for Eco-Environmental Sciences, Chinese Academy of Sciences, \\ P.O. Box 2871, Beijing 100085, China
}

\section{A R T I C L E I N F O}

\section{Article history:}

Received 7 July 2008

Received in revised form 4 September 2008

Accepted 8 September 2008

Available online 13 September 2008

\section{Keywords:}

Histamine

Automated on-line pre-column

derivatization

HPLC-FLD

Food

\begin{abstract}
A B S T R A C T
An improved sensitive method was developed and validated for the determination of histamine in food samples by using automated on-line pre-column derivatization coupled with high performance liquid chromatography and fluorescence detection (HPLC-FLD). $o$-Phthaldialdehyde (OPA) was adopted as derivatization reagent, and a "sandwich" (OPA + histamine + OPA) aspiration mode for the automated online pre-column derivatization was found to efficiently enhance the method sensitivity and precision. Histamine in food samples was efficiently extracted with a methanol-phosphate buffer solution (50:50, $\mathrm{v} / \mathrm{v}$ ) at $60^{\circ} \mathrm{C}$ for $30 \mathrm{~min}$, and purified with Waters Oasis MCX solid-phase extraction (SPE) cartridge. The limit of quantification for this method is $0.2 \mathrm{mg} / \mathrm{kg}$, which is very sensitive for histamine determination. With the "sandwich" injection program, 3.7\% of relative standard deviation (RSD) was achieved by five replicative determinations of a sample blank spiked with $0.25 \mathrm{mg} / \mathrm{kg}$ histamine standard. Histamine in food samples such as fumitory skipjack and mackerel was analyzed with relative recoveries over 95\% at spiking level of $150 \mathrm{mg} / \mathrm{kg}$, as well as canned tuna fish and cheese with relative recoveries up to $98 \%$ at spiking levels of 0.50 and $5.0 \mathrm{mg} / \mathrm{kg}$, respectively. The proposed method was validated with a sample from the Food Analysis Performance Assessment Scheme (FAPAS) as a standard certified material; and the results $(140 \pm 6 \mathrm{mg} / \mathrm{kg})$ agreed well with the assigned value $(139 \mathrm{mg} / \mathrm{kg})$.
\end{abstract}

(C) 2008 Elsevier B.V. All rights reserved.

\section{Introduction}

Histamine, the degradation product of histidine, is frequently found in fish tissues of the Clupeidae and Scombridae families. The natural level in fresh fish is less than $50 \mathrm{mg} / \mathrm{kg}$, but higher levels are found in decomposing fish due to the decarboxylation of histidine. Histamine is an indicator of deterioration in food, and is frequently regarded as one of the biomarkers for quality control during the food production and transportation. According to US Food and Drug Administration (FDA) Compliance Policy Guide Sec 54.525 , fish containing less than $10 \mathrm{mg} / \mathrm{kg}$ histamine is of good quality, whereas a level of $30 \mathrm{mg} / \mathrm{kg}$ indicates significant deterioration, and $50 \mathrm{mg} / \mathrm{kg}$ is considered to be a conclusive evidence of decomposition [1]. Because of its potential risk to health, a regulation level on histamine has been set in most of the countries or organiza-

\footnotetext{
* Corresponding author. Tel.: +86 10 62849192; fax: +86 1062923563 .

E-mail address: jfliu@rcees.ac.cn (J.-f. Liu).
}

tions. In the United States, the toxic level is set at $500 \mathrm{mg} / \mathrm{kg}$, and the caution level is $50 \mathrm{mg} / \mathrm{kg}$. The European Union has also set a caution level of $100-200 \mathrm{mg} / \mathrm{kg}$ for seafood, which was also proposed as regulations by the Codex [2]. In addition, histamine can also cause allergy-like food poisoning known as scombroid poisoning when the food consumed contains a large amount of histamine [3-6]. For very sensitive subjects, ingestion of 70-1000 mg per single meal may lead to death $[7,8]$. Tuna dumpling, ingested by the victims of food-borne poisoning during an incident in Taiwan in 2006, was found to contain more than $1000 \mathrm{mg} / \mathrm{kg}$ histamine [9]. Some other research papers also reported some accidents because of food-borne poisoning caused by histamine [10-13].

Determination of histamine in food is a topic of increasing interest in food chemistry, and methods including colorimetric [14], fluorometric [15], enzyme-linked immunosorbent assay (ELISA) [16], and chromatographic methods [17-23] were developed in the past decades. Among these methods, chromatographic technique is one of the most frequently used techniques. Although gas chromatography (GC) with flame ionization detection (FID) 
[17,18], electron capture detection (ECD) [19] or mass spectrometry detection (MSD) [20] were employed for the analysis of histamine, these methods suffered from complex matrix effects and sample carryover. On the contrary, HPLC coupled with different detectors provided better selectivity, sensitivity and reliability for the complex sample analysis [21-25]. HPLC with ultraviolet (UV) detection has low sensitivity for histamine detection. Consequently, pre-, post- and on-column derivatization methods are generally used to improve the detection sensitivity by using fluorescence detection (FLD). Among these three derivatization methods, the postand on-column methods result in broader peaks of derivatives than the pre-column method, due to the mixing process of the analyte and reagent in the derivatization reaction device [26]. oPhthaldialdehyde (OPA), dansyl chloride and fluorescamine are the three derivatization reagents mainly used for histamine determination. Compared with the other two reagents, dansyl chloride forms more stable derivative products but the derivative reaction takes about more than 15 min even under heating. Although the reaction between fluorescamine and histamine completes in a few minutes, but the product is unstable and more complex for separation with HPLC. As the reaction between OPA and histamine completes within $30 \mathrm{~s}$ in the presence of 2-mercaptoethanol at room temperature, pre-column derivatization with OPA is commonly adopted for HPLC-FLD analysis of histamine. However, critical conditions have to be controlled to eliminate the influence of the relative instability of the derivatives [27,28].

The matrix interferences in complex samples cannot be eliminated efficiently despite derivatization sometimes can improve the selectivity and sensitivity. Therefore, sample pretreatment steps are necessary to eliminate the interferences. Solid-phase extraction (SPE), as a commonly used sample preparation technique, has been widely used for the determination of histamine in food [24], wine $[21,25]$ or pharmaceutical [23]. For SPE $[21,25,29,30]$ of histamine with the most frequently employed $\mathrm{C} 18$ cartridge, the content of organic solvents in the elution solutions has to be low to avoid poor recoveries. The Waters Oasis MCX cartridge, containing a mixedmode polymeric sorbent with reversed-phase and cation exchange functionalities is reported to be very similar to the $\mathrm{C} 18$ sorbent but has higher selectivity for basic compounds and tolerance for organic solvents up to $50 \%$ in the elution solutions. These characteristics of MCX cartridge favor the removal of fat or protein and improve the extraction efficiency for some specific compounds.

In the present work, an improved method for the determination of histamine in complex food samples was developed. This method consists of the solid-phase extraction cleanup using a MCX cartridge, automated on-line pre-column derivatization within an autosampler, and the HPLC-FLD determination of histamine derivative at its characteristic fluorescence spectrum. The optimum cleanup procedure and the automated on-line derivatization procedure greatly improved the method sensitivity, reproducibility and throughput.

\section{Experimental}

\subsection{Reagents and chemicals}

HPLC-grade methanol and ethanol were purchased from Tedia (Fairfield, OH, USA). Histamine ( $\geq 97 \%$ ) was purchased from Sigma-Aldrich (Milwaukee, WI, USA). o-Phthaldialdehyde (Chromatographic grade) was purchased from Pickering Laboratories (Mountain View, CA, USA). 2-Mercaptoethanol (Analytical grade) was purchased from FARCO Chemical Supplies (Hong Kong, China). All of the other chemicals and solvents were of analytical reagent grade and ultrapure water $(18.3 \mathrm{M} \Omega \mathrm{cm})$ produced by a Milli-Q water system (Millipore, Billerica, MA, USA) was used throughout.

\subsection{Preparation of standard solutions and derivatization reagent}

Histamine stock solution ( $1000 \mathrm{mg} / \mathrm{L})$ was prepared by dissolving $0.025 \mathrm{~g}$ of the compound in $25.0 \mathrm{~mL}$ ultrapure water. OPA derivatization reagent was prepared by dissolving $25.0 \mathrm{mg}$ OPA, $1.0 \mathrm{~mL}$ methanol and $100 \mu \mathrm{L} 2$-mercaptoethanol in $10.0 \mathrm{~mL}$ potassium borate buffer $(10 \mathrm{mM}$, adjusted to $\mathrm{pH} 10.0$ by $1 \mathrm{M}$ potassium hydroxide). All the solutions were stored in brown glass bottles and kept at $4{ }^{\circ} \mathrm{C}$, and they were stable for up to seven working days.

\subsection{Sample collection and storage}

All the samples except the canned tuna fish-FAPAS were collected from the local manufactures that produced food for export. The canned tuna fish samples were mainly composed of tuna flesh and soup; the fumitory shipjack were made like dry powder or small grains; the mackerel were fresh, and the skins were removed, a piece of flesh was cut and ground with a food preparing machine (Hailing, Hangzhou, China); the cheese samples are dry strips about $5 \mathrm{~cm}$ long. The canned tuna fish-FAPAS samples were purchased from Beijing office of FAPAS, and the main ingredients were flesh gruel. All the collected or prepared samples were stored at $-18^{\circ} \mathrm{C}$ prior to further preparation and extraction.

\subsection{Sample preparation and extraction procedures}

About $5.0 \mathrm{~g}$ of food sample and $20 \mathrm{~mL}$ methanol-phosphate buffer $(1: 1, v / v)$ (the phosphate buffer was prepared with dissolving $50 \mathrm{mM}$ potassium dihydrogen phosphate in water) was added into a $50-\mathrm{mL}$ polypropylene centrifuge tube. The sample was homogenized with a Poly Tron Dispersing and Mixing apparatus (Kinematica, Littau-Luzern, Switzerland), shaken about 1 min with a vortex shaker (Scientific Industries, Bohemia, NY, USA), and extracted for $30 \mathrm{~min}$ in $60^{\circ} \mathrm{C}$ warm water under $100 \mathrm{rpm}$ by using a stable temperature horizontal shaking water bath, type GFL-1086 (GFL, Burwedel, Germany).

\subsection{Sample cleanup}

The extraction solution was centrifuged at $4000 \mathrm{rpm}$ for $10 \mathrm{~min}$ with Sigma 3K centrifuge (Sigma Laborzentrifugen, Osterode am Harz, Germany), thereafter $5 \mathrm{~mL}$ of supernatant was transferred to a new centrifuge tube and adjusted to about $\mathrm{pH} 4$ with $1 \mathrm{M}$ hydrochloric acid. Then, it was purified with Waters Oasis MCX SPE cartridge on a Supelco SPE apparatus (Supelco, Bellefonte, PA, USA) according the flowchart shown in Fig. 1. The eluent was evaporated to dryness with nitrogen blowing and reconstituted with ultrapure water for HPLC analysis.

\subsection{HPLC determination}

The HPLC equipment used was an Agilent 1200 LC system (Santa Clara, DE, USA) including a quaternary pump, a fluorescence detector (excitation: $345 \mathrm{~nm}$, emission: $445 \mathrm{~nm}$ ). A personal computer equipped with an Agilent ChemStation program for LC was used to process chromatographic data. An autosampler with a $100 \mu \mathrm{L}$ injection valve and a $150 \mathrm{~mm} \times 4.6 \mathrm{~mm}$ i.d. C18 column thermostated to $30^{\circ} \mathrm{C}$ (Cloversil Sciences, Irving, TX, USA, $5 \mu \mathrm{m}$ particles) were used for injection and separation of the analytes. The mobile phase was $60: 40(\mathrm{v} / \mathrm{v})$ water (with $1.2 \%$ triethylamine and $2.5 \%$ phosphoric acid): methanol, delivered at a flow rate of $1.0 \mathrm{~mL} / \mathrm{min}$. The isocratic elution was able to separate histamine derivative and other interferences completely in $15 \mathrm{~min}$. An optimized injection program used for the sample injection is described in Table 1 . 


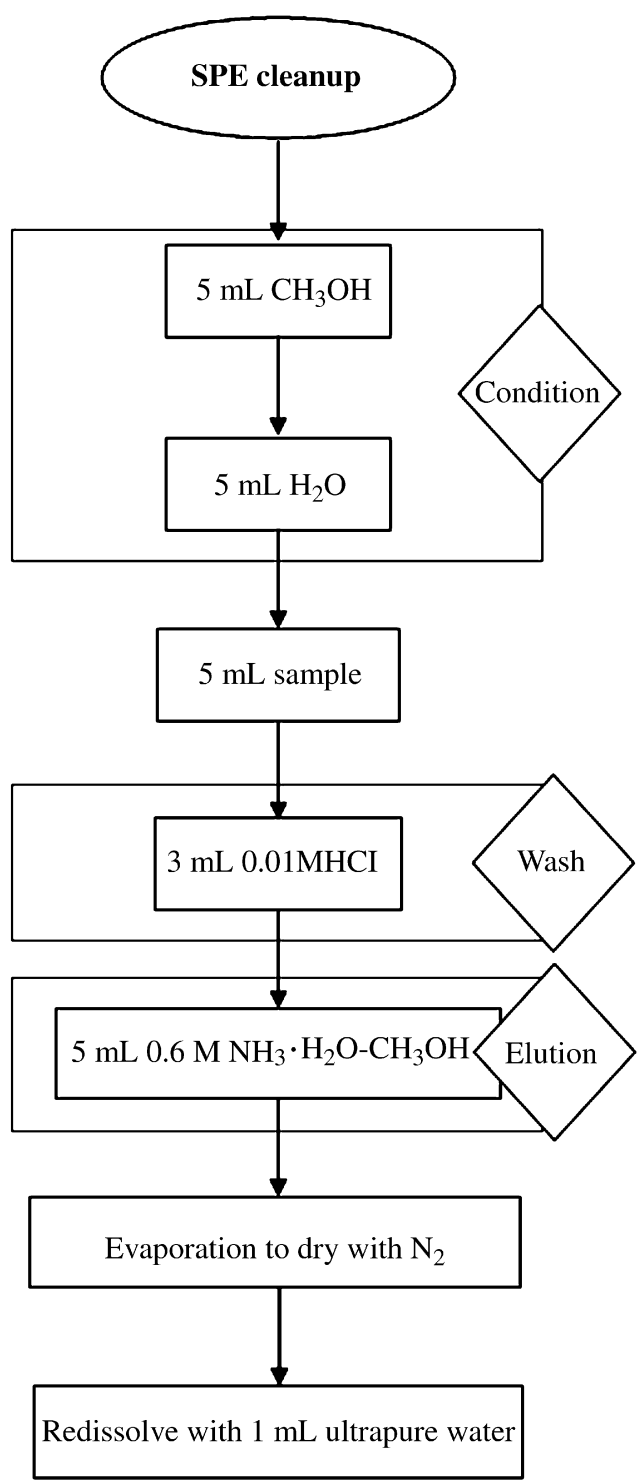

Fig. 1. Flow chart for the SPE cleanup.

\section{Results and discussion}

\subsection{HPLC separation}

For achieving good peak shape and improving the separation, a phosphate-triethylamine buffer and methanol were employed as the mobile phase. Some reverse HPLC columns, including Cloversil C18 column, Inertsil ODS- 3 column and Waters Xbridge C18 column were tested to separate histamine derivative from the complex food samples. No interferences were observed and good peak shape was achieved by the Cloversil C18 column.

Table 1

The optimized injection program for automated pre-column derivatization

\begin{tabular}{ll}
\hline Step & Command \\
\hline 1 & Draw $7.5 \mu \mathrm{L}$ from vial X (OPA) \\
2 & Needle wash in vial X $\left(\mathrm{H}_{2} \mathrm{O}\right), 3$ times \\
3 & Draw $10.0 \mu \mathrm{L}$ from sample \\
4 & Needle wash in vial X $\left(\mathrm{H}_{2} \mathrm{O}\right), 3$ times \\
5 & Draw $7.5 \mu \mathrm{L}$ from vial X (OPA) \\
6 & Mix max. amount in air, 3 times \\
7 & Inject \\
\hline
\end{tabular}

\subsection{Automated on-line pre-column derivatization}

\subsubsection{Aspiration mode of sample and OPA solutions}

In general, the derivatization reaction between histamine and OPA is instantaneous; however, the resultant product is unstable. During offline derivatization, the time and vortex intensity must be critically controlled to obtain good reproducibility. To overcome this drawback, we developed a novel on-line automated pre-column derivatization procedure by using the HPLC autosampler in this study. Keeping the sample and OPA volume constant and with the same mixing step (mixed 3 times between the last drawing and injection), a series of aspirating programs were tested for achieving optimum derivatization efficiency. Program (1): a $10 \mu \mathrm{L}$ sample (histamine) followed $15 \mu \mathrm{L} \mathrm{OPA}(10 \mu \mathrm{L}$ sample $+15 \mu \mathrm{L}$ OPA). Program (2): $7.5 \mu \mathrm{L}$ OPA $+10 \mu \mathrm{L}$ sample $+7.5 \mu \mathrm{L}$ OPA. Program (3): $5 \mu \mathrm{L} \mathrm{OPA}+5 \mu \mathrm{L}$ sample $+5 \mu \mathrm{L} \mathrm{OPA}+5 \mu \mathrm{L}$ sample $+5 \mu \mathrm{L}$ OPA. Program (4): $3 \mu \mathrm{L} \mathrm{OPA}+2.5 \mu \mathrm{L}$ sample $+3 \mu \mathrm{L}$ OPA $+2.5 \mu \mathrm{L}$ sample $+3 \mu \mathrm{LOPA}+2.5 \mu \mathrm{L}$ sample $+3 \mu \mathrm{LOPA}+2.5 \mu \mathrm{L}$ sample $+3 \mu \mathrm{L}$ OPA. The results showed that the highest response was achieved by program (2). This can be attributed to two aspects. On the one hand, segments between the samples with OPA reagent improved the mixing efficiency of sample and OPA and thus the analytical responses. On the other hand, with program (3) and program (4), drawing all of the OPA and samples takes much longer time. And the reaction between OPA and histamine in the early formed interface of every two segments was accomplished and degradation of histamine-derivative occurred when all of the drawing processes were finished. This caused the decrease of analytical responses. We further evaluated the mixing time and mixing way on the response, and results showed that a program described in Table 1 was the most efficient one and which was used in the following experiments.

\subsubsection{Optimization of the OPA concentration}

In general, the derivatization efficiency is improved with the increase of derivatization reagent concentration, whereas overloaded drivatization reagent may affect the determination of the target analyte. The OPA concentration was optimized with histamine at $50 \mu \mathrm{g} / \mathrm{mL}$ level and results are shown in Fig. 2, which indicates that the response increased with OPA concentration up to $15 \mathrm{mg}$ and then kept constant. For ensuring that higher concentra-

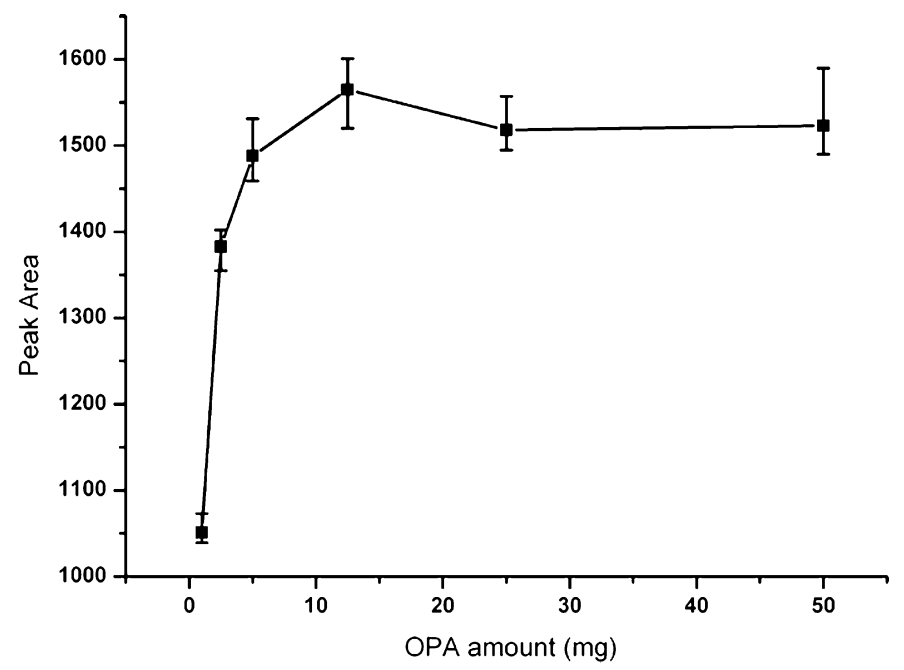

Fig. 2. Effect of OPA amounts on the peak area of histamine-OPA. OPA derivatization reagent was prepared by dissolving varied amount of OPA, $1.0 \mathrm{~mL}$ methanol and $100 \mu \mathrm{L} 2$-mercaptoethanol in $10.0 \mathrm{~mL}$ potassium borate buffer $(10 \mathrm{mM}$, adjusted to $\mathrm{pH} 12.0)$. 


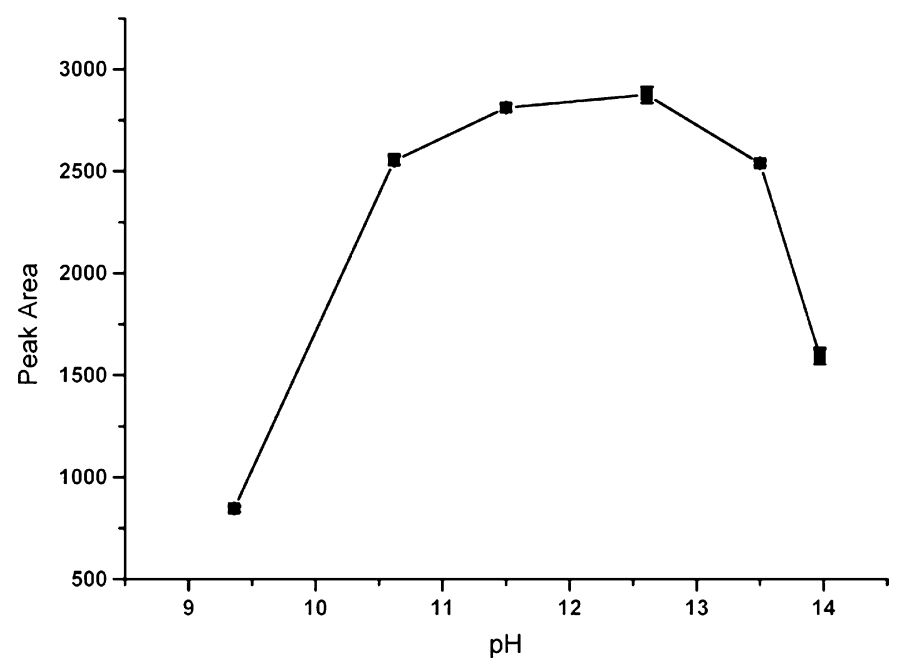

Fig. 3. Effect of $\mathrm{pH}$ on the peak area of histamine-OPA. OPA derivatization reagent was prepared by dissolving $25 \mathrm{mg}$ OPA, $1.0 \mathrm{~mL}$ methanol and $100 \mu \mathrm{L} \mathrm{2-}$ mercaptoethanol in $10.0 \mathrm{~mL}$ potassium borate buffer adjusted to $\mathrm{pH}$ 9.36-13.97.

tion of histamine can be fully derivatized, $25 \mathrm{mg}$ OPA was selected for the following experiments.

\subsubsection{Optimization of $p H$}

Because the derivatization reaction between histamine and OPA occurred in a microenvironment in this study, the $\mathrm{pH}$ of reaction media may affect the derivatization efficiency. According to the reaction mechanism between histamine and OPA, alkaline medium facilitates the derivatization reaction. A series of potassium borate buffer solutions ( $10 \mathrm{mM}$ ) adjusted to varied $\mathrm{pH}$ by adding potassium hydroxide were employed to optimize the $\mathrm{pH}$. Results shown in Fig. 3 indicate that the analytical responses increased with $\mathrm{pH}$ in the range of $\mathrm{pH} 9.36-10.62$, and then varied slightly with $\mathrm{pH}$ up to 12.61 , and decreased drastically with further increase of $\mathrm{pH}$. The decrease might be attributed to the decomposition of histamine derivative at strong basic conditions. Consequently, a pH 12.0 potassium borate buffer solution was used for the following experiments.

\subsection{Sample preparation}

\subsubsection{Extraction conditions}

Complete and selective extraction of target analytes from complex food samples is of great importance in food analysis. In this study, different extraction conditions including the extraction solvent, the extraction temperature and the extraction time were investigated.

Because of the high contents of fat in fish or other food samples, extraction solvents that can remove fat or protein are frequently selected for achieving high extraction efficiency. In these experiments, perchloric acid $(0.4 \mathrm{M})$, trichloroactic acid $(3 \%, \mathrm{~m} / \mathrm{v})$, hydrochloric acid $(0.1 \mathrm{M})$, methanol-water $(1: 1, \mathrm{v} / \mathrm{v})$, ethanol-water $(1: 1, v / v)$, and methanol-phosphate buffer $(1: 1$, $\mathrm{v} / \mathrm{v}$ ) were tested as extraction solvents for the standard certificated materials. Results revealed that more than 95\% extraction efficiency was obtained with methanol-phosphate buffer as the extraction solvent, but less than $90 \%$ of extraction efficiencies were achieved with the other five extraction solvents. Because the methanol-phosphate buffer extraction system provided good peak shape and effective separation, it was selected as the optimized extraction solution in the following experiments.

Temperature is an important condition for most of the extraction processes, because it has great influence on both the kinetic process

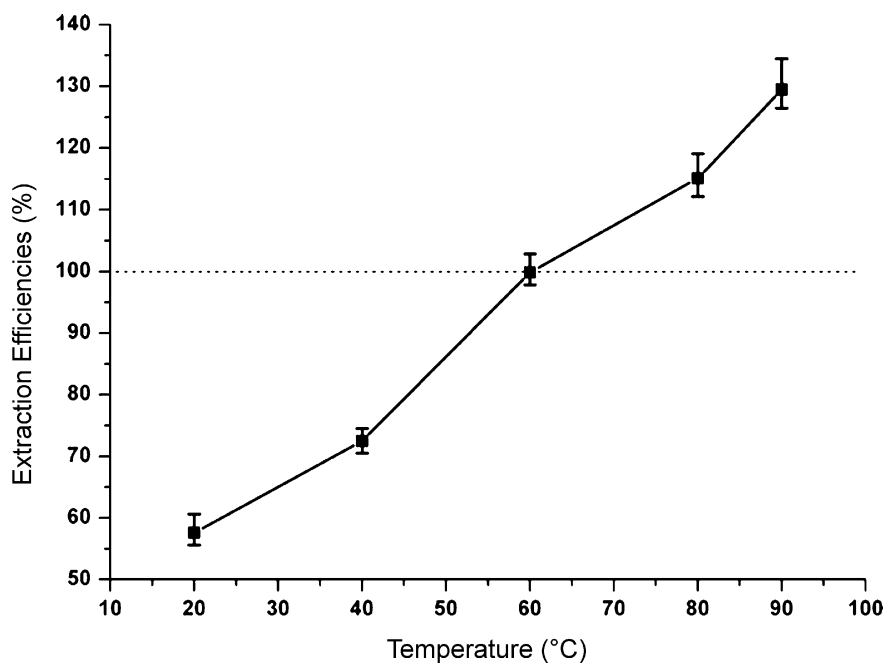

Fig. 4. Influence of temperature on the extraction efficiency. Sample was extracted for 30 min under varied temperature with $100 \mathrm{rpm}$.

and the thermodynamic process. To optimize the extraction temperature, standard certificated materials were extracted for $30 \mathrm{~min}$ with the methanol-phosphate extraction solution at varied temperature. As shown in Fig. 4, the extraction efficiency increased almost linearly with temperature. The over $100 \%$ extraction efficiency at above $60^{\circ} \mathrm{C}$ suggests extra histamine was produced at these high temperatures. Therefore, $60^{\circ} \mathrm{C}$ was selected as the optimized temperature for the following experiments.

The effect of extraction time was studied in the range of $10-90$ min by using standard certificated materials under the above-optimized conditions. Results showed that histamine was almost completely extracted from the samples with extraction time over $20 \mathrm{~min}$, and extra histamine was produced when the extraction time is longer than $50 \mathrm{~min}$. Consequently, $30 \mathrm{~min}$ was selected as the appropriate time for the real sample analysis.

\subsubsection{Cleanup with MCX cartridge}

Sample cleanup procedure takes an important role in elimination of the matrix effects and improvement of determination sensitivity. A series of frequently used cartridges such as C18, HLB were tested, but only less than $50 \%$ recoveries could be achieved. This may be attributed to the high methanol content $(50 \%, v / v)$ in the extract solutions, which resulted in the breakthrough of histamine when the extract solutions were passed through the "cleanup" cartridge. Considering histamine is a polar

Table 2

Histamine content in food samples (mean $\pm S D, n=3$ ) and the spiked recoveries $($ mean $\pm \mathrm{SD}, n=3)$

\begin{tabular}{lccc}
\hline Sample & \multicolumn{2}{c}{ Histamine content $(\mathrm{mg} / \mathrm{kg})$} & \multirow{2}{*}{ Recovery (\%) } \\
\cline { 2 - 3 } & Added & Found & \\
\hline \multirow{2}{*}{ Canned tuna fish } & 0 & $0.59 \pm 0.02$ & - \\
Fumitory skipjack & 0.50 & $1.08 \pm 0.03$ & $98 \pm 6$ \\
Mackerel & 0 & $127 \pm 7$ & - \\
Cheese & 150 & $273 \pm 8$ & $97 \pm 5$ \\
Canned tuna fish -FAPAS & 0 & $167 \pm 8$ & - \\
& 150 & $317 \pm 9$ & $100 \pm 6$ \\
& 0 & $5.31 \pm 0.33$ & - \\
& 5.0 & $10.2 \pm 0.3$ & $98 \pm 5$ \\
& 0 & $140 \pm 6$ & - \\
\hline
\end{tabular}

a FAPAS is part of the Central Science Laboratory (CSL), an executive agency of the UK Government Department for Environment, Food and Rural Affairs (Defra). 
basic compound, the sample solution was purified with a MCX SPE cartridge which plays both the cation exchange role and the reverse phase role. For evaluating the SPE procedure, $1.0 \mu \mathrm{g} / \mathrm{mL}$ histamine standard was loaded prior to the sample loading, and eluted as described in Fig. 1. Over 95\% of recoveries were achieved for the five replicative experiments, indicating this SPE cartridge is efficient in cleanup of these samples.

\subsection{Analytical performance and real sample analysis}

Under the optimized HPLC conditions, the analytical performance including the limit of detection (LOD), linear range, and repeatability were studied. A good correlation coefficient $\left(r^{2}>0.9999\right)$ was achieved with five standard solutions ranging from 0.05 to $100 \mu \mathrm{g} / \mathrm{mL}$, and a LOD of $10 \mathrm{ng} / \mathrm{mL}(\mathrm{s} / \mathrm{n}=5)$ of histamine was obtained. By analyzing a blank sample spiked with varied amount of histamine $(0.2-400 \mathrm{mg} / \mathrm{kg})$, the limit of quantification (LOQ) was determined to be $0.2 \mathrm{mg} / \mathrm{kg}$ histamine in samples $(\mathrm{s} / \mathrm{n}=10)$, and the chromatograms for the sardine with histamine blank and the sample spiked at $0.2 \mathrm{mg} / \mathrm{kg}$ histamine were shown in Fig. 5. By five replicative analyses of a blank sample spiked with $0.25 \mathrm{mg} / \mathrm{kg}$ histamine standard, the relative standard deviation (RSD) was 3.7\%. Both LOD and LOQ of this present method were lower than those reported in literature [24,31], and were comparable with those achieved by using high performance liquid chromatography tandem mass methods $[29,30]$.
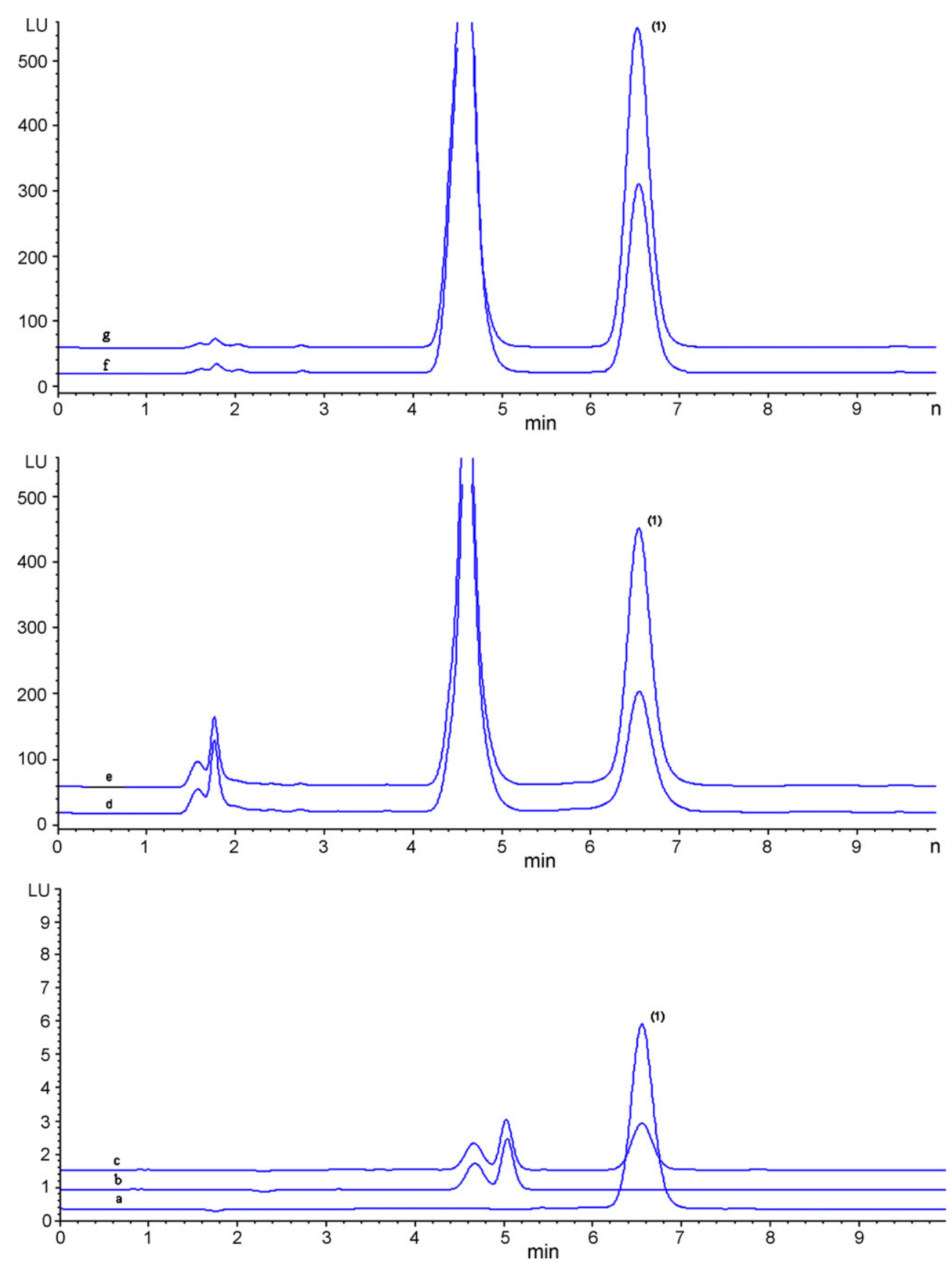

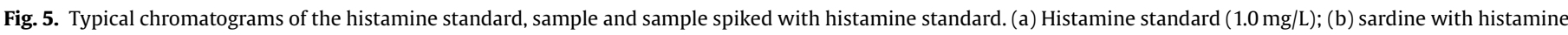

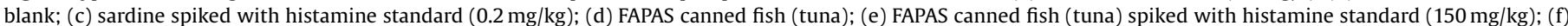
fumitory skipjack; (g) fumitory skipjack spiked with histamine standard (150 mg/kg); Peaks identified as: (1) histamine-OPA. 
Some food samples including canned fish (tuna), fumitory skipjack, mackerel, and cheese were analyzed. From the results shown in Table 2, we can see the histamine concentration was $167 \pm 8 \mathrm{mg} / \mathrm{kg}$ in mackerel and $127 \pm 7 \mathrm{mg} / \mathrm{kg}$ in fumitory skipjack, and the recovery was $100 \%$ and $97 \%$ at $150 \mathrm{mg} / \mathrm{kg}$ histamine spiking level. In the fresh canned tuna fish and cheese, however, only $0.59-5.31 \mathrm{mg} / \mathrm{kg}$ histamine can be found. For further evaluating the developed method, a FAPAS canned tuna fish sample was analyzed and the obtained result agreed well with the reference value. The representative chromatograms were shown in Fig. 5.

\section{Conclusions}

An automated on-line pre-column derivatization coupled with HPLC-FLD was proposed for the determination of histamine in complex food samples. The matrix effects are eliminated effectively by employing the appropriate SPE cleanup procedure, while the sensitivity, reproducibility and detection throughput are improved greatly with the developed automated on-line derivatization program. The proposed method was validated with the successful analysis of standard reference materials, as well as fish and cheese samples. In addition, because of easy operation and the fully automated HPLC determination, the method is especially suitable for food quality control in ordinary laboratories, or for batch analysis in regulatory departments.

\section{Acknowledgements}

This work was jointly supported by the National Natural Science Foundation of China (20577059) and Instrumental Analysis Foundation of Zhejiang (2007F70063).

\section{References}

[1] P.L. Rogers, W.F. Staruszkiewicz, J. Aquat. Food Prod. Technol. 9 (2000) 5.
[2] L. Lehane, J. Olley, Intl. J. Food Microbiol. 58 (2000) 1.

[3] S.H. Arnold, W.D. Brown, Adv. Food Res. 24 (1978) 113

[4] S.L. Taylor, Crit. Rev. Toxicol. 17 (1986) 91.

[5] S.L. Taylor, J.E. Stratton, J.A. Nordlee, J. Toxicol. Clin. Toxicol. 27 (1989) 225.

[6] S.F. Wu, W. Chen, Acta Paediatr. Taiwan 44 (2003) 297.

[7] S.L. Taylor, E.R. Lieber, M. Leatherwood, J. Food Sci. 43 (1978) 247.

[8] S.L. Taylor, S.S. Summer, Seafood Quality Determination, Elsevier, Amsterdam, 1987.

[9] H.C. Chen, H.F. Kung, W.C. Chen, W.F. Lin, D.F. Hwang, Y.C. Lee, Y.H. Tsai, Food Chem. 106 (2008) 612.

[10] S.C. Chang, H.F. Kung, H.C. Chen, C.S. Lin, Y.H. Tsai, Food Control 19 (2008) 16.

[11] Y.H. Tsai, H.S. Hsieh, H.C. Chen, S.H. Cheng, T.J. Chai, D.F. Hwang, Food Chem. 104 (2007) 1366

[12] Y.H. Tsai, H.F.K.H.C. Chen, S.C. Chang, H.H. Hsu, C.I. Wei, Food Chem. 105 (2007) 1289.

[13] Y.H. Tsai, H.F. Kung, T.M. Lee, H.C. Chen, S.S. Chou, C.I. Wei, D.F. Hwang, Food Control 16 (2005) 579.

[14] S.B. Patange, M.K. Mukundan, K.A. Kumar, Food Control 16 (2005) 465.

[15] Histamine in Seafood: Fluorometric Method, Section 35.1.32, Method 977.13, in: P.A. Cunniff (Ed.), Official Methods of AOAC International, 16th ed., Association of Official Analytical Chemists (AOAC) International, Gaithersburg, MD, 1995, p. 6.

[16] O. Aygun, E. Schneider, R. Scheuer, E. Usleber, M. Gareis, E. Martlbauer, J. Agric. Food Chem. 47 (1999) 1961.

[17] E. Evans, P.J. Nicholls, J. Chromatogr. 82 (1973) 394

[18] R. Tham, J. Chromatogr. 23 (1966) 207.

[19] P.S. Doshi, D.J. Edwards, J. Chromatogr. 176 (1979) 359

[20] J.O. Fernandes, I.C. Judas, M.B. Oliveira, I.M.P.L.V. Ferreira, M.A. Ferreira, Chromatographia 53 (2001) 327.

[21] E.H. Soufleros, E. Bouloumpasi, A. Zotou, Z. Loukou, Food Chem. 101 (2007) 704.

[22] V. von Vietinghoff, G. Gabel, J.R. Aschenbach, J Chromatogr. B 844 (2006) 335.

[23] N.H. Kim, Y. Park, E.S. Jeong, C.S. Kim, M.K. Jeoung, K.S. Kim, S.H. Hong, J.K. Son, J.T. Hong, L. Park, D.C. Moon, Arch. Pharm. Res. 30 (2007) 1350.

[24] S. Oguri, M. Enami, N. Soga, J. Chromatogr. A 1139 (2007) 70.

[25] C. Proestos, P. Loukatos, M. Komaitis, Food Chem. 106 (2008) 1218.

[26] S. Oguri, Y. Yoneya, J. Chromatogr. B 781 (2002) 165.

[27] C.M.C.J. van Haaster, W. Engels, P.J.M.R. Lemmens, G. Hornstra, G.J. van der Vusse, J. Chromatogr. 617 (1993) 233.

[28] R. Hakanson, A.L. Ronnberg, K. Sjolund, Anal. Biochem. 47 (1972) 356.

[29] V. Gianotti, U. Chiuminatto, E. Mazzucco, F. Gosetti, M. Bottaro, P. Frascarolo, M.C. Gennaro, J. Chromatogr. A 1185 (2008) 296.

[30] F. Gosetti, E. Mazzucco, V. Gianotti, S. Polati, M.C. Gennaro, J. Chromatogr. A 1149 (2007) 151.

[31] B.S. Hwang, J.T. Wang, Y.M. Choong, Food Chem. 82 (2003) 329 